\title{
OBSERVACIONES
}

\section{sobre la inducción al trabajo del parto por la administración del Pitocin Endovenoso}

\author{
Por el doctor MAMUEL JOSE GOMEZ PALACINO
}

En la mayoría de las observaciones verificadas para este estudio, la dosis inicial empleada para la indueción al trabajo del parto por la administración de Pitocín endovenoso, ha sido de 3 unidades diluídas en 500 c. c. de solución Dextrosada al 5 o $10 \%$, en agua : solución salina; esta mezcla se aplica por venoclisis y la frecuencia inicıal ha sido variable, pero en casi todos los cesos, al comienzo del goteo, no fue inferior a 50 gotas por minuto. Una vez instalado el gota a gota, por palpacióu se aprecia el momento en que aparece al aumento del tono uterivo, el cual se manifiesta en forma uniforme, generalizado e indoloro; en ocasiones las pacientes anotan seusación de simple "tirantez' lumbar o hipogástrica. Estit hipertonía constituye el primer signo de actividad uterina $y$ generalmente aparecen entre los 2 y los 5 minutos siguientes a la iniciación del goteo. (En un caso la contracción de la matriz se hizo aparente a los 10 minutos; y en 2, inmediatamente). Aparecido este signo, se reduce la frecuencia del gota a gota $y$ se continúa yor palpación controlando la actividad uterina. La hipertonía que anuncia la proximidad de las contrac. ciones de la matriz se prolonga por varios minutos, hasta 7 , y va seguida de m período de relajación compensadora. Cuando la relajatión tarda en aparecer y la consistencia de la matriz indica un atumento de tono muy marcado, se suspende temporal o definitivamente el empleo de la solución inductora si ei trabajo continúa. Pasado el período de relajación, las contracciones se suceden con ritmo de cada $2-3$ minutos y con 20 a 30 segundos de duración; desencadenado en estas condiciones el trabajo, se gradủa el goteo de manera que este ritmo se sostenga hasta el momento en que los controles indiquen que la dosis es suficiente $y$ que no existe la posibilidad de que al suspenderse el suministro de Dextrosa Pitocin, el trabajo se paralice. $S i$ se desea, la administración puede continuarse hasta el alumbramiento.

Este ritmo de 2 a 3 minutos es susceptible de modificarse, según que se acelere o retarde el número de gotas al minuto administradas.

Establecidas la frecuencia y duracióu de las contracciones, el control se reduce a vigilar los ruídos fetales y la activi- 
tunamente modifi ?r el trabajo, si las circunstancias así lo exigen.

En 40 de las 50 historias aquí publicadas figuran controles con intervalos de media $n$ una hora de la tensión artecial y puso de la paciente; por los datos en ellas consignados, se deduce que esios controles son secundarios, pues las variaciones encontradas no fueron amplias, pudiéndose considerar ellas dentro de lo normal.

En los casos en que las contracciones se sucedieron con intervalos inferiores a 2 minutos, o se pudo apreciar alguna modificación en los ruídos fetales, se redujo o suspendió la aplicación de la solución inductora por un lapso más o menos largo y suficiente para lograr que el trabajo se desarrollara en mejores condiciones y sin riesgos. El criterio de impedir que los dolores se repitan con intervalos inferiores a los 2 minutos es el de evitar la tetanización con los consiguientes peligros para la madre $y$ el feto.

Una vez desencadenado el trabajo en forma franca, dato obtenido por la intensidad de los dolores y la duración de las contracciones, pues, vale anotar que el tipo de trabajo logrado por este sirtema es muy aproximado al fisiológico que se observa cuando las contracciones se desencadenan espontáneamente. se deben verificar los tactos necesarios paia poder valorar la efectividad de las contracciones; de acuerdo con los datos obtenidos se continúa o suspende la solución $y$ se administran o no medica. inentos adyurantes, del tipo espasmolítico o analgésico si se desea.

Aún cuando para la gran mayoría de !as inducidas, la primera dosis fue suficiente, en el resto se hizo indispensa- apreciar que al suspender la solución, las contracciones se repetían cada vez rás distanciadas y de más corta dura‘ión. De las 50 observadas, 13 necesitaron una segunda dosis y 5 a quienes se les aplicó una dosis mayor; en las 13 al terminarse el primer frasco, los datos ubtenidos por el tacto revelaban cuello blando, borrado y con una dilatación que oscilaba entre 2 y 5 centímetros: en ostas condiciones realmente no se podia concluír si el trabajo continuaria, se suspendería o se prolongaría demasiado, al suprimir definitivamente la aplicación de la mezcla inductora. Estas posibiiidades no se podían experimentar en este tipo de pacientes, todas de clientela eivil.

Al segundo frasco, se le adicionaron: a 4 la misma dosis, a 4 el doble $y$ a 5 una dosis simplemente mayor. Las variaciones en la dosis con el deseo de evitar el recargo de líquidos administrados endovenosamente.

Por demás está advertir que cuanto mayor sea la dosis de Pitocín diluidas, rás baja será la frecuencia del gota a gota, al menos al iniciar la segunda dosis. pues se trata de buscar y controlar tolerancia y beneficios; en algunos casos la frecuencia fue mayor una vez instalada la venoclisis, y pasado un tiempo prudencial; todo depende de las condicrones en que se esté desarrollando al trabajo, pues al aumentar la dosis de Pitocin puede perseguirse también como finalidad lograr contracciones más efectivas.

Hubo 3 pacientes, primíparas, para quienes la segunda dosis no fue suficien1e: una recibió en los primeros 500 c. c. 3 unidades, 4 en el segundo y en el tercero 5 unidades; de este último única- 
Ifthle se te aprearun ou c. c. y se suspendió cuando la dilatación era compieta y la paciente sintió sensación de pujo. La segunda recibió 3 unidades la primera vez, 3 en el segundo frasco y se transladó a la Sala de Partos, con un tercer frasco adicionado de otras 3 unidades: allí se encontró cuello comple. tamente borrado y con 5 centimetros de dilatación; se le continuó el gota a gota, ol cual le the retirado cuando la dilatación era completa. De este tercer frasco. recibió aproximadamente 300 c. $\bullet$ f.a tercera recibió: 3 unidades en el primero, 4 unidades en el segundo $\mathbf{y}$ unidades en el tercero; con la primera dosis hizo rasi completo borramiento del cuello y dilatación de 2 centímetros; con la segunda dosis la efectividad de las contracciones fue nula y lo mismo puede anotarse de la tereera. En vista de los resultados obtenidos, se le aplicaron: Demerol una ampolleta intramuscular, 2 ampolletas de Trasentina y un suposicorio de Atrinal; con esta medicación e] trabajo se suspendió. Dos horas y media de suprimida toda droga, reanudó contracciones espontáneamente, dolorosas y con frecuencia de cada $7 \mathrm{mi}$ untos; así se la dejó trabajar durante 21 horas, al cabo de las cuales se transsadó a la sala de partos, con cuello blando, delgado, 3 centímetros de dilatación y presentación de vértice por subre el estrecho superior. En la sala se rompiewon artificialmente las membranas y se pindo apreciar la expulsión de liquido amniótico teñido de meconio; digita!mente se completó la dilatación y se terninó el parto con aplicación de fórceps por sobre el estrecho superior, con diasnóstico de sufrimiento fetal en presentación no encajada.
Los pacientes, ambas multiz...antes viejas (46 años), sexto y séptimo embarazo, respectivamente, recibieron: la una 35 unidades de Pitocín administradas en la siguiente forma: 15 unidades diluídas en 1.500 c. c. en el término de 10 horas 35 minutos. Por la noche, durmió y a la mañana siguiente se le ordenó: purgante con 40 gramos de aceite de ricino, inyección de 10.000 midades de Foliculina y un comprimido de Metrazol-quimina, cada media hora, hasta completar 6, sin resultados. Se le aplicaron entonces en un primer frasco de 500 c. c., 10 unidades de Pitocín en una hora 40 minutos y a continuación. 5 unidades en otros 500 c. c. en una hora 50 minutos, sin resultados ni complicacioines. En vista de los repetidos fracasos se le autorizó el regreso a su casa; alli y a las 31 horas de suspendida toda melicación hubo ruptura espontánea de las membranas sin trabajo; previa consulta con su médico, ingresó de nuevo a la clínica. En tales circunstancias y en aissencia de trabajo se le aplicaron 10 unidades de Pitocín en 1.000 c. c. de solución Dextrosada, dosis suficiente para hacer parto espontáneo. La señora sufrió de shock obstétrico el que le fue combatido con 250 c. c. de plasma analépticos y oxígeno. El niño nació en perfectas condiciones.

La segmnda gestante habia sido indurida en dos ocasiones consecutivas por el método aconsejado por Tatson con complito fracaso; se le administraron 17 uniadas de Pitocín en 3.000 c. c. de suero (un día 8 unidades en 1.000 c. c. $y$ al siguiente 9 unidades en 2.000 $\therefore$ (., sin resultados); terminó en operación cesárea. La insistencia del método en estas dos paciontes se debió a qu. respondian a la inducción como las otras 
senoras, con contracomoses de sgual ritmo y duración, pero el trabajo :ne inefectivo. Ninguna tuvo dolores francos. De las 32 pacientes para quienes el primer frasco de Dextrosa-Pitocín, o parte de él, fue suficiente, la cantidad de Pitocín mezclada a $\operatorname{los} 500$ c. c. de suero, fue:

En 2 casos: 1 unidad.

En 1 caso: $2 \frac{1}{2}$ unidades.

En 24 casos: 3 unidades.

En 1 caso: $3 \frac{1}{2}$ unidades.

En 2 casos: 4 unidades.

En 2 casos: 5 unidades.

Al repasar las historias de estas pacientes, se puede concluír que el factor dosis de Pitocín es muy relativa $\mathbf{y}$ variable en cuanto a efectividad, $y$ así, en 3cs 2 casos en que la cantidad de Pitocín era de 1 unidad en 500 c. c., la aplicación del gota a gota se suspendió cuan. do el volumen del suero inyectado era is 109 y 200 c. c. respectivamente; naturalmente, es necesario tener en cuenta la indicación de la administración: la paridad de la encinta, la edad, la presentación y todos los demás factores que intervienen en el desarrollo del trabajo y en el mecanismo del parto. La paciente que recibió 100 c. c. (0,2 unidades), ن.a una multigestant barazo y se le aplicó la solución por inercia secundaria. La segunda, primipara, con dilatación del cuello de 5 centínetros $y$ después de romperle artificialmente las menbranas; al verificar Esta maniobra se encontró el líquido amniótico teñido de meconio y la presenta"lón por sobre el estrecho superior. A pesar de estos datos, recibió con buena tolerancia la solución inductora, $200 \mathrm{c}$ ๔., es decir, 0,4 unidades de P'itocín, dosis mediante la cual se consiguió com-

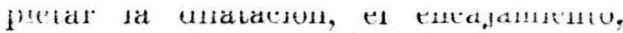
lescenso y rotación a $\mathrm{O}$. P. de la presen. tación.

Es lógico pensar que cuando se trata de emplear este método en primíparas, se debe ser muy cauto, pues en ellas ni siquiera se puede sospechar el tipo do trabajo que han de desencadenar.

Cuando la dosis de Pitocín fue de 5 unidades se trataba de multigestantes. ambas de 30 años de edad. cuarto embarazo y con antecedentes de partos normales; la una recibió 125 c. c., es decir, 1,25 unidades y la otra 70 c. c. 0.7 uniàades.

Entre las gestantes del grupo que turo necesidad de la segunda dosis, una. vez terminado el primer frasco, figura una paciente en que se pudo apreciar lo siguiente: a los 500 c. c. iniciales se les mezcló una unidad de Pitocín y comenzó trabajo con ritmo de contracciones cada $2 \frac{1}{2}$ minutos; a las 2 horas, la Precuencia de las contracciones era de cada 7 minutos, y con el deseo de aproximarlas se aumentaron a 60 las gotas por minuto. Como con este aumento del erateo, las modificaciones del ritmo no. fieron apreciables, al mismo frasco se le agregaron 3 unidades más de Pito$\therefore$ in; a los $3 / 4$ de hora $y$ con 48 gotas al minuto, las contracciones se repetían cada dos minutos. Esto indica la slisceptibilidad del método de poderlo noiificar en cualquier momento $y$ segúi e' criterio del especialista, y la dificu?tad encontrada al tratar de determinar iosis útiles.

Con el fin de demostrar la disparidad de dosis necesarias en cada caso particular, así como también las variaciones en tiempo suficiente para llegar a auto. rizar el traslado de la paciente a la sala de partos, se ha elaborado un 
ontrega, en el cual se encuentran discriminados los detalles fundamentales de las 24 embarazadas para quienes fue suficiente la dosis de 3 unidades po: 500 •. •. Las que figuran sin dilatación: completa, se hicieron trasladar a it simplemente sedarlas con la adumistración de ciclo, o completarles digitalmen. te la dilatación del cuello, y aligerar en psta forma el parto.

\section{REVISTA DE REVISTĀS}

Le pouvoir antiproteolytique du scrum en practique obstetricale et gynecologique.

Par H. Vignes. Gynecologie et obstetrique. Paris. T. 49, No 2. 50.

Un problema en obstetricia es la determinación de la etiología del aborto espontáneo, pues, la sífilis y las alteraciones de la estática uterina, no los exrican todos. Por eso, el A., ha fijado su atención sobre el poder antiproteolitico del suero, que aumenta durante el mibarazo y aporta algunas luces sobre e) intrincado tema.

Desde que Shute dijo que algumos abortos se debian a la resistencia de la cadnca contra la fijación de las vellosidades, Vignes, junto con Roger Le Breton, se dedicé a analizar el poder antiproteolítico del suero; utilizó en el laboratorio a más del suero por investigar fibrina desecada de cerdo y pancreatina y estableció que la norma investigativa consistía en determinar al porcentaje de fibrina no proteolizada e!i e] curso de la experiencia y calcularlo dosificando los aminoácidos libertados, siguiendo el método de Sorensen.
(Continuará) 